\title{
Research on the Construction of Innovative Enterprise Culture
}

\author{
Yangzhihao Lei \\ Weinan Longhai High School, China. \\ 1106840892@qq.com
}

\begin{abstract}
Innovative enterprise culture is an important driving force of enterprise innovation. Based on the analysis and summary of the connotation of the innovative enterprise culture and internal and external influencing factors, this paper puts forward suggestions on cultivating innovative enterprise culture, and provides certain reference significance for the enterprise management practice.
\end{abstract}

Keywords: Innovative enterprise culture; influencing factors; countermeasures and suggestions.

\section{Connotation of Innovative Enterprise Culture}

Corporate culture is a complex of unique business concepts and norms (Schwartz, Davis, 1981) formed in long-term business operation. Innovative enterprise culture is an excellent enterprise culture, which includes management and operation concepts that keep pace with the times. Innovation culture can help organizations achieve high performance goals by arousing employees' enthusiasm, initiative and sense of responsibility. Innovative enterprise continue to develop and advance through innovation in its management mode and means. Innovative enterprise culture combines four different values at the same time, namely the entrepreneurial spirit of adventure, the participation of employees in enterprise decision-making, the technological innovation and the cohesion of enterprise.

Innovative enterprise culture is also very comprehensive and inclusive. Innovative enterprise culture is one of the types of enterprise culture, and there are studies that have focused on two different perspectives of innovative enterprise culture. The first category of concerns shows the perspective that the innovative enterprise culture regards innovation as the core content, which embodies the integrity and strictness of the enterprise's rules and regulations, and humanized characteristics, including innovative values, guidelines, systems and specifications. The other category focuses on the enterprise atmosphere. This perspective believes that the innovative enterprise culture can stimulate and cultivate enterprise innovation. Innovation culture needs to establish a cultural environment conducive to innovation. Whether technology, knowledge or system innovation, they all need corresponding mechanism system and cultural environment (Frohman, 1998). From these two perspectives, innovative enterprise culture is a combination of enterprise value concept, operation concept, moral code and code of conduct with innovation as the core. It is an enterprise culture type that can stimulate, cultivate and promote innovation activities.

\section{Influencing Factors for the Formation of Innovative Enterprise Culture}

The cultivation of innovative enterprise culture is formed by the joint efforts of external factors and internal factors for a long time. The internal factors are divided into four parts: entrepreneurship, management system, innovation of employees and organizational management structure. External factors consist of three parts: social culture, institutional environment and global environment.

\subsection{Internal Factors}

\subsubsection{Entrepreneurship}

Entrepreneurship has distinctive innovative characteristics. The establishment of enterprise is the process of entrepreneurs discovering opportunities and constantly implementing innovation. At the same time, entrepreneurship is also reflected in the ability to take risks and integrate resources (Coven, Levin, 1991). In enterprises, entrepreneurs play an important role in making major decisions for the team and establishing various management systems. To a large extent, the innovation atmosphere and rules and regulations have an impact on the sustainable innovation of enterprise culture. Innovation 
spirit is the core of entrepreneurship and the most basic requirement of modern enterprise system for the quality of entrepreneurs.

\subsubsection{Management System}

System culture is the embodiment of enterprise culture. Scientific system culture design can make enterprises have more efficient management and deployment of human resources. Management system has the characteristic of flexibility, which is reflected in the humanized design of the system itself. It can make different system differentiation for different departments and institutions, and maximize the innovation potential of different employees. It can ensure the rapid flow and transformation of innovative thinking and promote mechanism innovation (Amabile, 1997). Enterprises should take full account of the influence of the system on the innovation culture in the system construction so that the enterprise system can promote organizational innovation.

\subsubsection{Innovation of Employees}

The innovation of employees is also an important factor influencing the innovative enterprise culture. Only when employees are innovative, adventurous and have a common sense of responsibility, can they effectively stimulate the emergence of innovative ideas in work and provide new vitality for enterprises. Employee creativity is an important internal driving force of enterprise innovation and will have a direct impact on enterprise performance. The creative training of enterprise employees is to encourage creative thinking, improve the ability of independent learning of employees, innovate products in practice, and challenge the problems that may arise in product research and development. It also can promote real-time communication and exchange of important ideas among employees, and help enterprises develop new products. It allows all employees to develop a sense of management and self-thinking.

\subsubsection{Organizational Management Structure}

Hierarchical management is used in traditional enterprises. This wide chain model is not conducive to the rapid transmission of information within the organization. The decisions of managers and the ideas of grassroots employees cannot be communicated in a timely manner, which may lead to the low information flow rate of the whole company. Innovative enterprises generally use a flat management chain, which is conducive to enhancing the participation of grassroots employees in decision-making and making innovation activities more frequent. Employees are also more likely to be authorized in flat management chain, which further stimulates the innovation of employees and the speed of enterprise information transmission (Claver, Lopes, Garcia, Molina, 1998).

\subsection{External Factors}

\subsubsection{Social Culture}

As an important part of society, enterprises are rooted in different regional cultures. Enterprises in different countries present different regional characteristics. At the same time, social culture also plays a direct role in the various elements within enterprises. Scholar Hofstede put forward five dimensions, namely, power distance, individualism, uncertainty avoidance, masculinity, long-term orientation dimension, to determine the cultural characteristics of different countries (Hofstede, Neuijen Okay, Sanders, 1990). Different regional culture types will influence the formation of innovative enterprise culture, such as preference for certainty, which will only pursue stability, settle in the status quo, and not encourage risk-taking. People's long-term orientation is obvious, they can tolerate immediate failure, and they have a strong sense of collectivism, which is conducive to the participation of all people in innovation.

\subsubsection{Institutional Environment}

Institutional environment is also an important factor influencing the formation of innovative enterprise culture. The flexible and innovative external institutional environment is more conducive to innovation of employees in the enterprise system. Moreover, only in this flexible institutional environment, can the innovation and autonomy of employees be stimulated and the cultivation of 
innovative enterprise culture be accelerated. The innovative atmosphere of the institutional environment will have an impact on the system design and personnel vitality of enterprises.

\subsubsection{Global Environment}

More and more enterprises need to face internationalized resources and markets to operate, and the competition among enterprises is more and more globalized. Under the background of internationalization, the enterprise management activities will face the diversified characteristics of suppliers and consumers, and the combination and integration of different cultures will facilitate the formation of innovation culture.

\section{Countermeasures and Suggestions for Innovative Enterprise Culture Construction}

\subsection{Seek Innovative Entrepreneurs}

In addition to a certain knowledge reserve accumulation, enterprise leaders should also have the innovative thinking of breaking the old and pushing forward the new. They should know how to cultivate and build innovative enterprise structure and system, and they should be able to create a more active communication environment to facilitate the information exchange and communication of enterprise employees. They should innovate with new ideas, improve the company's management system and communication methods. In addition, in the process of enterprise innovation, the leadership of an enterprise should work hard to eliminate the shackled thinking, the hierarchical concept that hinders innovation, the conservative and legacy thinking, and take the lead in practical management of innovation activities.

\subsection{Implement the Concept of Innovative Enterprise Culture Into the System Design}

One of the ways to embody the innovative enterprise culture is its rules and regulations. In the process of system design, it is necessary to integrate the values of innovative enterprise culture into the system design. Enterprise system is the foundation of innovative enterprise culture. It requires the following six aspects to implement the innovative concept in the system design. First, use the guiding role of system design to determine the direction of enterprise innovation. Secondly, make full use of the cohesive force of the incentive system to mobilize the initiative of employees for innovation. Thirdly, make use of the radiation effect of system design to maximize the role of innovative enterprise culture. Fourthly, the internal control system of an enterprise shall cover all the business and matters of the enterprise, throughout the whole process of decision-making, execution and supervision. Enterprise management involves both the corporate level and the business level. Both the governance level and the management level, as well as each business level, must follow the rules. Fifthly, the system should adapt to the principle of enterprise development. When designing the internal control system of an enterprise, it is necessary to take the operation scale, business scope, competition status and risk level into consideration, and make timely adjustment as the situation changes. Sixthly, when designing the system, the principle of program positioning should be ensured. The enterprise shall, in accordance with the nature and characteristics of its economic business, designate key control points and several specific posts for its operation and management activities, and assign responsibilities and authorities accordingly according to the nature of the posts, stipulate operating rules and define inspection standards.

\subsection{Encourage the Innovation of Employees}

On the basis of the new enterprise management system established by the leader, in the innovative enterprise culture, employees need to have a comprehensive and profound understanding of the connotation and system of the enterprise innovation culture. Employees need to learn relevant skills, improve their knowledge structure, cultivate their awareness of innovation and enrich their means of innovation, to help enterprises achieve the goal of innovation (Negroponte, 2003). Enterprises should promote employee innovation from the following three aspects. First, create a good environment to 
protect innovation. Create an environment conducive to creativity of employees. Educate and encourage grassroots employees to go the way no one has gone before. Make everyone dare to innovate to become a trend. Encourage grassroots employees to generate new ideas, form new concepts and create new products. Secondly, form an effective new talent incentive mechanism. Encourage grassroots employees to love their posts and study hard, and establish a sense of innovation, so as to carry out innovation activities in a long term. Thirdly, correctly guide the direction of innovation. Set the direction of innovation around the production development, set the innovation project around the production target, set the innovation standard around the production need, and make the innovation result be applied to the production management in time.

\subsection{Establish Flat Organizational Structure}

In flat organizational structure, employees' information transmission speed is fast and flexibility is strong, which is conducive to the cultivation of innovative corporate culture. In order to promote enterprise innovation, the following three points should be noted in organizational structure design. First, in order to improve the communication efficiency of flat organization, organization must change their ideas, establish a "people-oriented" flexible management concept, respect personality differences among different individuals, and support employees to realize their own value through self-discipline and continuous learning. It needs to advocate democratic autonomy and knowledge sharing, fully empower and stimulate the creativity of employees, so as to increase the sense of mission and belonging of employees and create a good organizational atmosphere for communication. Secondly, managers of flat organizations must master excellent working skills and communication skills, constantly provide emotional support for employees, and encourage employees to give full play to their subjective initiative and pay attention to feedback. Each member of the organization should not only know his own business scope, but also know all the information of the business modules in the team, so as to improve the ability of each member to analyse and solve problems independently, and to promote the information sharing and joint learning of team members. Therefore, the enterprise should regularly train and educate employees and managers in working ability and communication skills, and continuously improve the comprehensive quality of the members in the organization to finally realize the efficient operation of the organization business. Thirdly, because the communication channels in the flat organizational structure are numerous, the leadership relationship is not clear. Without strict codes of conduct in advance, it is easy to lead to poor communication efficiency and blur the boundary between authority and responsibility. In order to avoid the above problems, enterprises must formulate standardized work procedures and communication plans in advance to ensure that the organizational structure is conducive to promoting enterprise innovation.

\section{Acknowledgements}

Thank for the National Social Science Foundation of China (Item NO. 17BGL098).

\section{References}

[1]. Schwartz, H., \& Davis, S. M. (1981). Matching corporate culture and business strategy. Organizational dynamics, 10(1), 30-48.

[2]. Frohman, A. L. (1998). Managers at work: Building a culture for innovation. ResearchTechnology Management, 41(2), 9-12.

[3]. Coven, J. G., \& Levin, D. P. (1991). A conceptual model of entrepreneurship as firm behavior. Entrepreneurship theory and practice, 16(1), 7-26.

[4]. Amiable, T. M. (1997). Motivating creativity in organizations: On doing what you love and loving what you do. California management review, 40(1), 39-58. 
[5]. Claver Cortés, E., Lopes, J., Garcia Bravo, D., \& Molina Minchin, H. (1998). Organizational culture for innovation and new technological behavior.

[6]. Hofstede, G., Neuijen, B., Okay, D. D., \& Sanders, G. (1990). Measuring organizational cultures: A qualitative and quantitative study across twenty cases. Administrative science quarterly, 286316.

[7]. Negroponte, N. (2003). Creating a culture of ideas. Technology Review, 106(1), 34-35. 